\title{
Growth-associated hyperphosphatemia in young recipients accelerates aortic allograft calcification in a rat model
}

\author{
Haruo Yamauchi, MD, PhD, ${ }^{\mathrm{a}}$ Noboru Motomura, $\mathrm{MD}, \mathrm{PhD},{ }^{\mathrm{a}}$ Ung-il Chung, $\mathrm{MD}, \mathrm{PhD},{ }^{\mathrm{b}}$ \\ Masataka Sata, MD, PhD, ${ }^{\mathrm{c}}$ Daiya Takai, MD, PhD, ${ }^{\mathrm{d}}$ Aya Saito, MD, PhD, ${ }^{\mathrm{a}}$ Minoru Ono, MD, PhD, ${ }^{\mathrm{a}}$ and \\ Shinichi Takamoto, MD, $\mathrm{PhD}^{\mathrm{a}, \mathrm{e}}$
}

\begin{abstract}
Objectives: Cardiovascular allografts in the young have limited durability because of early graft calcification. The objective of this study was to examine the hypothesis that growth-associated hyperphosphatemia in youth accelerates aortic allograft calcification by osteogenic transformation of graft medial smooth muscle cells (SMCs).
\end{abstract}

\begin{abstract}
Methods: The descending aortas of donor rats were subcutaneously transplanted into recipients. Syngeneic (Lewis-to-Lewis) transplantations between 3-week-old "young" (Y) rats and between 10-week-old "adult" (A) rats were combined with standard (ST, $0.9 \%$ phosphate) and low-phosphate (LP, $0.2 \%$ ) diets, resulting in Y-ST, Y-LP, and A-ST groups. Allotransplantations (Brown-Norway-to-Lewis) involving these ages and diets were also made. The grafts and sera were retrieved from recipients after 14 days. Cultured rat aortic SMCs were used to analyze the effects of tumor necrosis factor-alpha (TNF- $\alpha$ ) and phosphate on SMC calcification.
\end{abstract}

Results: In vivo, serum phosphate levels were higher in Y-ST $(11.5 \mathrm{mg} / \mathrm{dL})$ than those in Y-LP $(8.9 \mathrm{mg} / \mathrm{dL})$ and A-ST $(8.5 \mathrm{mg} / \mathrm{dL})$. Graft medial calcification appeared severe only in Y-ST. Allotransplants did not affect these outcomes. Graft medial cells showed phenotypic changes (contractile to synthetic) and osteogenic transformation ( $\alpha$-smooth muscle actin to Runx 2 and osteocalcin), together with up-regulated proinflammatory TNF- $\alpha$ and sodium-phosphate cotransporter, Pit-1, despite ages and diets. In vitro, TNF- $\alpha$ induced phenotypic changes and osteogenic transformation of SMCs with Pit-1 up-regulation, but SMC calcification occurred only with high phosphate $(4.5 \mathrm{mmol} / \mathrm{L})$.

Conclusions: Growth-associated hyperphosphatemia with inflammatory responses may be essential for accelerating allograft calcification in youth and could be a therapeutic target. ( $\mathrm{J}$ Thorac Cardiovasc Surg 2013;145:522-30)

Allografts have been useful in cardiovascular surgery for several decades, offering advantages of tissue compatibility, hemodynamics, and avoidance of long-term anticoagulant therapies. ${ }^{1}$ However, accelerated graft degeneration and calcification in young patients, especially neonates and infants, limit their durability. ${ }^{2-5}$ Immunoreactions may have roles in allograft degeneration, ${ }^{5}$ but the etiology of accelerated allograft calcification in young patients is still unidentified.

\footnotetext{
From the Department of Cardiothoracic Surgery, ${ }^{a}$ Division of Tissue Engineering, ${ }^{b}$ and Department of Clinical Laboratory, ${ }^{\mathrm{d}}$ The University of Tokyo Hospital, Tokyo, Japan; the Department of Cardiovascular Medicine, ${ }^{\mathrm{c}}$ University of Tokushima, Tokushima, Japan; and the Department of Cardiovascular Surgery, ${ }^{\mathrm{e}}$ Mitsui Memorial Hospital, Tokyo, Japan.

This work was supported by "Kakenhi": Grant-in-Aid for Scientific Research (C: 19591615).

Disclosures: Authors have nothing to disclose with regard to commercial support.

Received for publication Dec 22, 2011; revisions received Feb 9, 2012; accepted for publication March 12, 2012; available ahead of print April 19, 2012.

Address for reprints: Haruo Yamauchi, MD, PhD, 300 Longwood Ave, Boston, MA 02115 (E-mail: hyamauchi-tky@umin.ac.jp).

$0022-5223 / \$ 36.00$

Copyright (c) 2013 by The American Association for Thoracic Surgery

doi:10.1016/j.jtcvs.2012.03.010
}

Vascular calcification has recently been recognized to arise from active osteogenesis. ${ }^{6}$ Uremic vasculopathy is characteristic of accelerated medial calcification (Mönckeberg sclerosis), particularly when accompanied with hyperphosphatemia and inflammation. ${ }^{7}$ In vitro, inorganic phosphate $(\mathrm{Pi})$ induced vascular smooth muscle cell (SMC) calcification by transforming SMC phenotypes from the myogenic lineage, such as $\alpha$-smooth muscle actin ( $\alpha$-SMA), to the osteogenic lineage, such as Runx2/Cbfa1 (a transcriptional factor for osteoblastic differentiation) and osteocalcin (noncollagenous bone protein), via type 3 sodium-phosphate cotransporters, Pit-1. ${ }^{8-10}$ Tumor necrosis factor-alpha (TNF- $\alpha$ ), a proinflammatory cytokine mainly secreted by macrophages, orchestrates inflammatory responses in uremic arteriopathy ${ }^{11}$ and also provokes in vitro vascular SMC calcification by osteogenic transformation. ${ }^{12,13}$

Unlike uremia, in which hyperphosphatemia is induced mainly by impaired $\mathrm{Pi}$ excretion, growth-associated hyperphosphatemia is characteristic of positive bone turnover in the young inasmuch as growth hormone promotes Pi reabsorption and inhibits the intact parathyroid hormone (iPTH) effect of Pi excretion in the kidney 


$$
\begin{aligned}
& \text { Abbreviations and Acronyms } \\
& \alpha \text {-SMA } \quad \alpha \text {-smooth muscle actin } \\
& \text { A-allo-ST }=\text { adult allogeneic-transplant with } \\
& \text { standard diet } \\
& \text { A-ST }=\text { adult syngeneic-transplant with } \\
& \text { standard diet } \\
& \mathrm{BN}=\text { Brown-Norway } \\
& \text { cAMP/PKA = cyclic adenosine monophosphate/ } \\
& \text { protein kinase } \mathrm{A} \\
& \mathrm{CD}=\text { cluster of differentiation } \\
& \text { HP = high inorganic phosphate } \\
& \text { iPTH = intact parathyroid hormone } \\
& \text { LP = low inorganic phosphate (diet) } \\
& \text { PCR = polymerase chain reaction } \\
& \mathrm{Pi}=\text { inorganic phosphate } \\
& \text { POD }=\text { postoperative day } \\
& \text { RAOSMC }=\text { rat aortic smooth muscle cell } \\
& \text { SMC }=\text { smooth muscle cell } \\
& \text { ST } \quad=\text { standard (diet) } \\
& \text { TNF- } \alpha=\text { tumor necrosis factor-alpha } \\
& \text { Y-allo-ST = young allogeneic-transplant with } \\
& \text { standard diet } \\
& \text { Y-ST = young syngeneic-transplant with }
\end{aligned}
$$

tubules. ${ }^{14}$ This leads to a higher prevalence of vascular calcification in young uremic patients. ${ }^{7}$ In a rat model, the involvement of growth-associated hyperphosphatemia in warfarin-induced arterial calcification was suspected, although its detailed mechanisms were not elucidated. ${ }^{15}$ We therefore hypothesize that growth-associated hyperphosphatemia accelerates allograft calcification in young recipients by the osteogenic transformation of graft SMCs in collaboration with the TNF- $\alpha$-mediated inflammatory response against the grafts. To examine this hypothesis, we used a rat aortic subcutaneous transplant model and a rat aortic SMC (RAOSMC) culture system.

\section{MATERIALS AND METHODS}

\section{Animals and Diets}

Three-week-old "young" male Lewis rats $\left(\mathrm{RT} 1 \mathrm{~A}^{1} \mathrm{~B}^{1}\right)$ and BrownNorway (BN) rats $\left(\mathrm{RT} 1 \mathrm{~A}^{\mathrm{n}} \mathrm{B}^{\mathrm{n}}\right.$ ) weighing 50 to $60 \mathrm{~g}, 10$-week-old "adult" male Lewis $(270-290 \mathrm{~g})$ and $\mathrm{BN}(200-220 \mathrm{~g})$ rats were purchased from Charles River Laboratories Japan (Yokohama, Japan) 1 week before experimentation. A standard (ST) rat diet $(0.9 \%$ of $\mathrm{Pi}, 1.1 \%$ of calcium) and a low $\mathrm{Pi}(\mathrm{LP}) \operatorname{diet}(0.2 \% \mathrm{Pi}, 1.1 \%$ calcium) were obtained from Oriental Yeast (Tokyo, Japan). ${ }^{16}$

\section{Rat Aortic Subcutaneous Transplant Model}

Rats were anesthetized with intraperitoneal pentobarbital (Nembutal; Hospira, Inc, Lake Forest, Ill; $35 \mathrm{mg} / 100 \mathrm{~g}$ body weight). Under sterile conditions, the descending aortas of the donor rats were harvested and kept in heparinized saline $\left(4^{\circ} \mathrm{C}\right)$ as fresh grafts until they were implanted in the subcutaneous pockets of the recipients' abdomens, as described elsewhere. ${ }^{17}$ The time from harvest to implantation did not exceed an hour. Each recipient rat received subcutaneous ampicillin $(10 \mathrm{mg} / 100 \mathrm{~g}$ body weight) once in its back.

Aortic transplantation was performed between the young rats (the young group) and, separately, between the adult rats (the adult group). Syngeneic (Lewis-to-Lewis) and allogeneic (BN-to-Lewis) transplantations were performed in each age group. Young recipients were fed an ST or an LP diet, whereas adult recipients and all donors received an ST diet throughout the experimental period, resulting in syngeneic- and allogeneic-transplant young (Y-ST and Y-allo-ST) and adult (A-ST and A-allo-ST) groups, all receiving an ST diet, and young groups receiving an LP diet (Y-LP and Y-allo-LP). The young and adult groups before transplantation were defined respectively as the Preop-Y and Preop-A groups. At postoperative day (POD) 7 and POD 14 for the Y-ST group and at POD 14 for the other groups, the recipients were anesthetized as described above, and the grafts were retrieved ( $n=6$ per group). Then, all recipients were humanely killed by cardiac puncture and the sera were immediately separated by centrifugation. The retrieved grafts and sera were promptly analyzed as follows. Anesthetic and surgical protocols were approved by the Ethics Committee on Animal Research of the University of Tokyo.

\section{Serum Test}

The serum calcium, Pi, and iPTH of each rat were measured by the $o$-cresolphthalein complexone method ${ }^{18}$ (Calcium C-test; Wako, Osaka, Japan), by the phosphate molybdenum blue method ${ }^{19}$ (Phosphor C-test; Wako), and with a rat total iPTH enzyme-linked immunosorbent assay kit (Scantibodies Laboratory, Santee, Calif), respectively. Radioimmunoassays of serum vitamin D [1,25-dihydroxycholecalciferol; $\left.1,25(\mathrm{OH})_{2} \mathrm{D}\right]$ were performed by SRL, Inc (Tokyo, Japan).

\section{Immunohistochemistry, von Kossa Staining, and Electron Microscopy of Grafts}

A 4- $\mu \mathrm{m}$ thick frozen section of each graft was examined immunohistochemistry, ${ }^{20}$ using primary antibodies against $\alpha$-SMA (clone 1A4; SigmaAldrich, St Louis, Mo), cluster of differentiation 68 (CD68) (AbD Serotec, Oxford, United Kingdom), Runx2 (Sigma-Aldrich), and osteocalcin (Santa Cruz Biotechnology, Santa Cruz, Calif). The positive controls were rat spleen (CD68) and fetal spine (Runx2 and osteocalcin), and the negative control was isotype-matched normal immunoglobulin. Graft calcification was detected by von Kossa staining. Microstructures were observed by transmission electron microscopy (H-7000; Hitachi, Tokyo, Japan) performed as described elsewhere. ${ }^{21}$

\section{Quantification of Calcium and Pi in Grafts}

The calcium content of grafts was quantified by atomic absorption spectroscopy ${ }^{22}$ by SRL. The tissue Pi content was measured by the Phosphor C-test ${ }^{19}$ (Wako). The amounts of calcium and of Pi in each graft were expressed as milligrams per dry weight in grams.

\section{Real-Time Polymerase Chain Reaction (PCR) of Grafts}

Total RNA was extracted from each graft tissue and real-time PCR was performed ${ }^{20}$ using the following target gene primer sequences: $\beta$-actin, (forward) 5'-ATTGAACACGGCATTGTCACC-3' (reverse) $5^{\prime}$-GCAT GAGGGAGCGCGTAAC-3'; $\alpha$-SMA, (forward) $5^{\prime}$-GAGAAGCTGCTC CAGCTATGT- $3^{\prime}$ (reverse) $5^{\prime}$-GATGATGCCGTGTTCTATCG- $3^{\prime}$; TNF- $\alpha$, (forward) $5^{\prime}$-TCCAGAACTCCAGGCGGTGT-3' (reverse) 5'-GGCAAA TCGGCTGACGGTGT-3'; Pit-1, (forward) 5'-GTCTGGTTCTTCGTA TGTCCC-3' (reverse) 5'-GAACTGAACAAGGTTCCCATTA-3'; Runx2, (forward) $\quad 5^{\prime}$-ATTCCTCATCCCAGTATGAGAGTAGGT-3' (reverse) 
5'-GCCCAGTGCCCCGTGT-3'; and osteocalcin, (forward) 5'-GAGG GCAGTAAGGTGGTGAATA-3' (reverse) $5^{\prime}$-AACGGTGGTGCCATA GATG- ${ }^{\prime}$. For osteocalcin determination, betaine monohydrate (SigmaAldrich) was added to the PCR solution because of its rich guaninecytosine content. ${ }^{23} \mathrm{~A}$ duplicate run for each sample was tested and the average was used. The messenger RNA expression of each graft was calculated and expressed as a ratio of that of the internal control, $\beta$-actin.

\section{Immunocytochemistry}

A cell culture system was prepared as described elsewhere. ${ }^{8,10}$ RAOSMCs (Cell Applications, San Diego, Calif) cultured in glassbottom dishes (Matsunami, Osaka, Japan) were subdivided into a TNF $(+)$ group with $50 \mathrm{ng} / \mathrm{mL}$ of TNF- $\alpha$ (Sigma-Aldrich) and a TNF(-) group without it. Mouse osteoblasts (JCRB1178; Health Sciences Foundation, Tokyo, Japan) were cultured without TNF- $\alpha$. After 7 days, cells were doublestained with $\alpha$-SMA combined with Runx2, osteocalcin, or normal immunoglobulin, using primary antibodies against $\alpha$-SMA (clone 1A4, Cy3-conjugated, Sigma-Aldrich), Runx2, and osteocalcin (as described in "Immunohistochemistry"). Each dish with cultured cells was blocked with horse serum and incubated overnight at $4{ }^{\circ} \mathrm{C}$ with the primary antibodies. Then, the secondary antibodies for Runx 2 and osteocalcin labeled with Alexa488 were applied and each dish was observed under a confocal laser scanning microscope (FV300; Olympus, Tokyo, Japan).

\section{Von Kossa Staining and Electron Microscopy of RAOSMCs}

RAOSMCs subdivided into TNF(+) and TNF(-) groups as well as mouse osteoblasts were combined with high $\mathrm{Pi}(\mathrm{HP}, 4.5 \mathrm{mmol} / \mathrm{l})$ and low Pi (LP, $1.5 \mathrm{mmol} / \mathrm{L})$ media by adding $\mathrm{Pi}\left(\mathrm{NaH}_{2} \mathrm{PO}_{4} / \mathrm{Na}_{2} \mathrm{HPO}_{4} ; 0.1 \mathrm{mmol} / \mathrm{L}, \mathrm{pH}\right.$ 7.0, Wako). After 14 days, cells were fixed and subjected to von Kossa staining. ${ }^{8}$ The same groups of RAOSMCs, after 7 days of culture, were fixed, gathered, and centrifuged to form a white pellet, which was treated for transmission electron microscopy. ${ }^{21}$

\section{Calcium Content in RAOSMCs}

$\mathrm{Pi}$ at $1.5,2.5,3.5$, and $4.5 \mathrm{mmol} / \mathrm{L}$ was administered on RAOSMCs subdivided into $\mathrm{TNF}(+)$ and $\mathrm{TNF}(-)$ groups. After 14 days, the calcium content of RAOSMCs was determined by the Calcium C-test ${ }^{18}$ (Wako) and standardized by their protein content. ${ }^{8}$

\section{Real-time PCR of RAOSMCs}

RAOSMCs were divided into 6 groups, to which TNF- $\alpha$ was administered in respective concentrations of $0,0.1,1,10,50$, and $100 \mathrm{ng} / \mathrm{mL}$ for 7 days. Then, RNA was extracted with an RNA mini kit (Qiagen, Duesseldorf, Germany), and real-time PCR was performed ${ }^{20}$ for $\beta$-actin, $\alpha$-SMA, Runx2, osteocalcin, and Pit-1.

\section{Statistical Analysis}

Measurements were presented as mean \pm standard error of the mean. Statistical significance was evaluated by analysis of variance, followed by comparisons between control and experimental conditions by the Dunnett test or the Tukey-Kramer honestly significant difference test among multiple groups, using JMP version 9 (SAS Institute, Inc, Cary, NC).

\section{RESULTS}

Effects of Young Age, Alloantigen, and Dietary Phosphate Restriction on Graft Calcification

In the young syngeneic- and allogeneic-transplant groups on a standard diet (Y-ST and Y-allo-ST groups), von Kossa staining revealed severe medial calcification, but none in the preoperative young (Preop-Y) and adult (Preop-A) groups, and little or none in the young posttransplant groups on a low phosphate diet (Y-LP and Y-allo-LP) or the adult groups (A-ST and A-allo-ST), irrespective of the presence of alloantigen (Figure 1, A). The calcium content of the grafts was significantly higher in the Y-ST and Y-allo-ST groups than in the others (Figure 1,B). Similar results were observed in graft $\mathrm{Pi}$ content in the syngeneictransplant groups (Figure 1,C). These findings suggest that young age encourages graft calcification regardless of the degree of immunoreaction.

\section{Body Weight and Serum Parameters Relevant to Tissue Calcification}

The rats' body weights in the Y-LP and Y-allo-LP groups showed growth retardation. The Y-ST group had, as serum factors relevant to calcium metabolism, higher $\mathrm{Pi}$ and lower iPTH levels than the A-ST group, whereas calcium and $1,25(\mathrm{OH})_{2} \mathrm{D}$ were not significantly different. In the Y-LP group, $\mathrm{Pi}$ and $\mathrm{iPTH}$ were significantly lower and calcium and $1,25(\mathrm{OH})_{2} \mathrm{D}$ higher than in the Y-ST group. Similar differences owing to age factors and dietary Pi inhibition were observed in the allogeneic group, although calcium and $1,25(\mathrm{OH})_{2} \mathrm{D}$ tended to be higher than in the syngeneic group (Table 1). These results suggest that only the serum Pi level reflects the severity of graft calcification.

\section{Microstructures of the Graft Medial Cells}

To investigate why young age encourages graft calcification, we further examined syngeneic grafts of both age groups. On electron microscopy, the graft medial cells in both age groups appeared flat preoperatively, with cytoplasms rich in actin filaments, typical characteristics of the contractile phenotype of SMCs (Figure 2, $A$ and $B$ ). The intracellular actin filaments appeared diminished in size and number, but were still present at POD 7 (Figure 2,C), although further diminished in both age groups at POD 14 (Figure 2, D and E). Postoperatively, however, matrix vesicles, characteristic of the synthetic phenotype of SMCs, appeared in the cytoplasm, and matrices were partially secreted into the extracellular spaces in both groups. Dense calcium deposition was observed in the Y-ST group (Figure 2, $C$ and $E$ ), whereas the margins of matrices were only slightly calcified in the A-ST group (Figure 2, D). In the Y-LP group, as in the Y-ST group, matrix vesicles were present, but without calcified matrices (Figure 2, F).

\section{Gene Expressions of the Graft Media}

Immunohistochemical staining showed that the graft media preoperatively expressed abundant $\alpha$-SMA, but no CD68, Runx2, or osteocalcin in either age group. Postoperatively, $\alpha$-SMA was much less expressed in the grafts, 


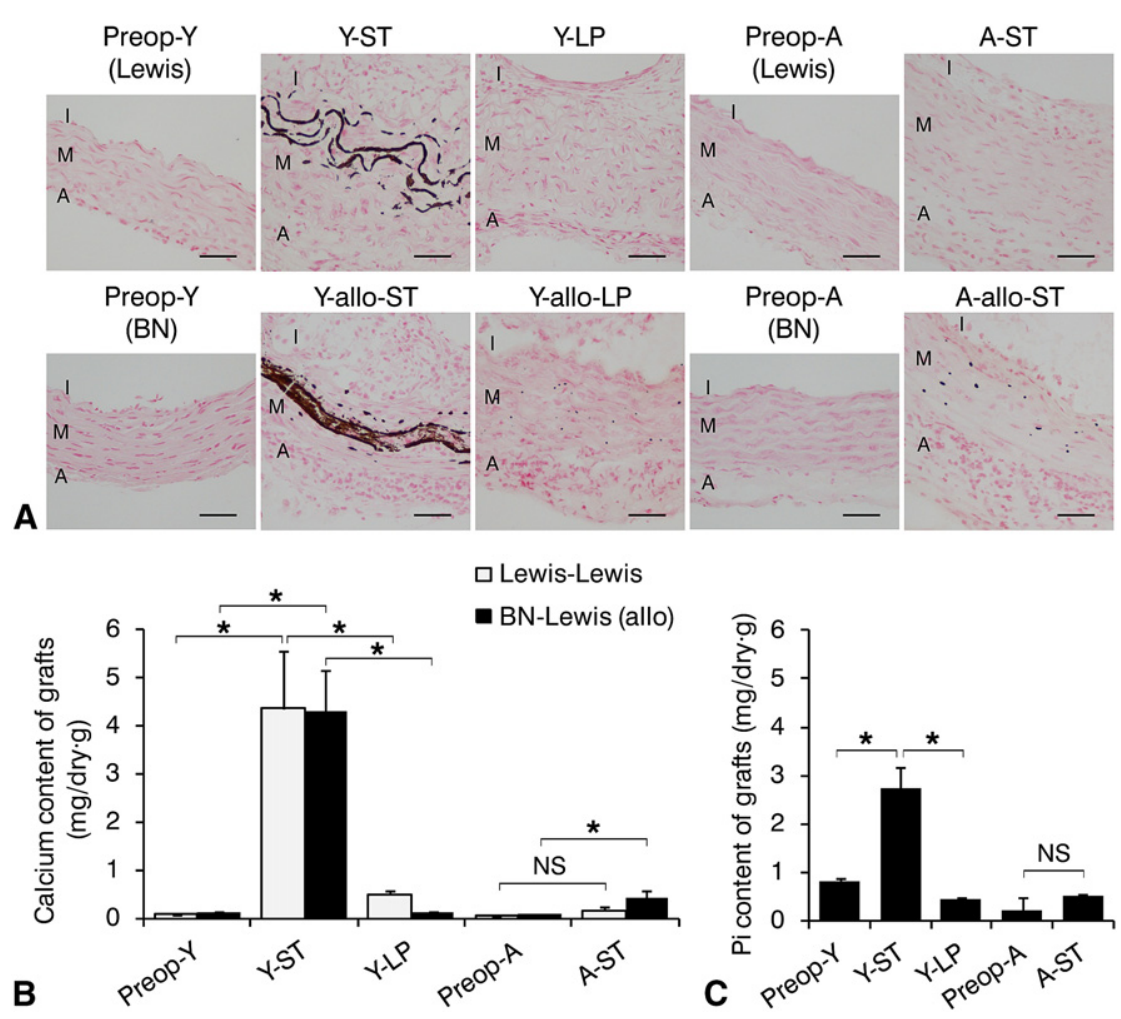

FIGURE 1. Analyses of aortic graft calcification. A, Von Kossa staining of the grafts showing calcification in black. Preop-Y and Preop-A, Preoperative young and adult groups; $Y$-ST and $Y$-allo-ST, young syngeneic- and allogeneic-transplant groups at postoperative day $(P O D) 14$ on a standard (ST) diet, respectively; $Y$ - $L P$ and $Y$-allo- $L P$, young syngeneic- and allogeneic-transplant groups, respectively, on a low phosphate $(L P)$ diet; $A$-ST and $A$-allo-ST, syngeneic- and allogeneic-transplant adult groups on an ST diet, respectively. $B N$, Brown-Norway; $I$, intima; $M$, media; $A$, adventitia. Magnification $\times 200$. Bar $=100 \mu \mathrm{m}$. B and C, Calcium and inorganic phosphate $(P i)$ contents of grafts ( $\mathrm{n}=6$ per group). $* P<.05$ by Tukey-Kramer honestly significant difference test; NS, not significant.

whereas CD68-positive macrophages appeared in and around the graft media. Runx2 and osteocalcin were also stained along the elastic graft media laminae (Figure 3, A). In real-time PCR, mRNA expression of $\alpha$-SMA was down-regulated, whereas those of TNF- $\alpha$, Pit-1, Runx2, and osteocalcin were up-regulated in the postoperative Y-ST, Y-LP, and A-ST groups. However, there were no significant differences among the Y-ST, the Y-LP, and the A-ST groups, except that Runx2 was significantly higher in the A-ST than in the Y-ST group (Figure 3, $B-F$ ).

\section{Coeffects of TNF- $\alpha$ and Phosphate on Rat Aortic SMCs}

The role of SMCs in graft calcification was examined using the RAOSMC culture. First, we investigated the effects of TNF- $\alpha$ on RAOSMCs. Immunocytochemistry

TABLE 1. Body weight and serum parameters of rat aortic transplant models

\begin{tabular}{lccccc}
\hline & Body weight $(\mathbf{g})$ & Calcium $(\mathbf{m g} / \mathbf{d L})$ & $\mathbf{P i}(\mathbf{m g} / \mathbf{d L})$ & $\mathbf{1 , 2 5}(\mathbf{O H})_{\mathbf{2}} \mathbf{D}(\mathbf{p g} / \mathbf{m L})$ & $\mathbf{i P T H}(\mathbf{p g} / \mathbf{m L})$ \\
\hline Preop-Y & $55.0 \pm 1.7^{*}$ & $8.7 \pm 0.4^{*}$ & $10.2 \pm 0.6$ & $274.2 \pm 18.2$ & $201.1 \pm 25.8$ \\
Y-ST & $117.7 \pm 2.5$ & $10.9 \pm 0.2$ & $11.5 \pm 0.6$ & $346.5 \pm 10.6$ & $264.3 \pm 15.5$ \\
Y-LP & $89.0 \pm 2.5^{*}$ & $13.6 \pm 0.8^{*}$ & $8.9 \pm 0.4^{*}$ & $846.2 \pm 83.8^{*}$ & $69.4 \pm 10.6^{*}$ \\
Y-allo-ST & $125.7 \pm 1.6$ & $12.7 \pm 0.1$ & $10.5 \pm 0.4$ & $465.3 \pm 17.2$ & Not examined \\
Y-allo-LP & $99.7 \pm 2.9^{*}$ & $16.2 \pm 0.4^{*}$ & $8.9 \pm 0.7^{*}$ & $971.0 \pm 20.1^{*}$ & Not examined \\
Preop-A & $281.3 \pm 3.3^{*}, \dagger$ & $10.0 \pm 0.3$ & $8.1 \pm 0.3^{*}$ & $237.0 \pm 30.7$ & $385.4 \pm 36.0 \dagger$ \\
A-ST & $304.7 \pm 1.6^{*}$ & $11.0 \pm 0.2$ & $8.5 \pm 0.3^{*}$ & $251.0 \pm 24.7$ & $721.6 \pm 84.2^{*}$ \\
A-allo-ST & $322.7 \pm 2.9^{*}, \dagger$ & $15.5 \pm 1.2^{*}, \dagger$ & $8.5 \pm 0.3^{*}$ & $389.7 \pm 20.1 \dagger$ & Not examined \\
\hline
\end{tabular}

The data represent mean \pm standard error (n $=6$ per group). $P i$, Inorganic phosphate; $1,25(\mathrm{OH})_{2} \mathrm{D}, 1,25$-dihydroxycholecalciferol; $i P T H$, intact parathyroid hormone; Preop- $Y$, young group before transplantation; $Y$-ST, young syngeneic-transplant with standard diet; $Y$ - $L P$, young syngeneic-transplant with low inorganic phosphate diet; $Y$-allo-ST, young allogeneic-transplant with standard diet; $Y$-allo- $L P$, young allogeneic-transplant with low inorganic phosphate diet; Preop-A, adult group before transplantation; $A$-ST, adult syngeneic-transplant with standard diet; $A$-allo-ST, adult allogeneic-transplant with standard diet. $* P<.05$ vs Y-ST in both age groups. $\dagger P<.05$ vs A-ST in the adult group by the Dunnett method. 

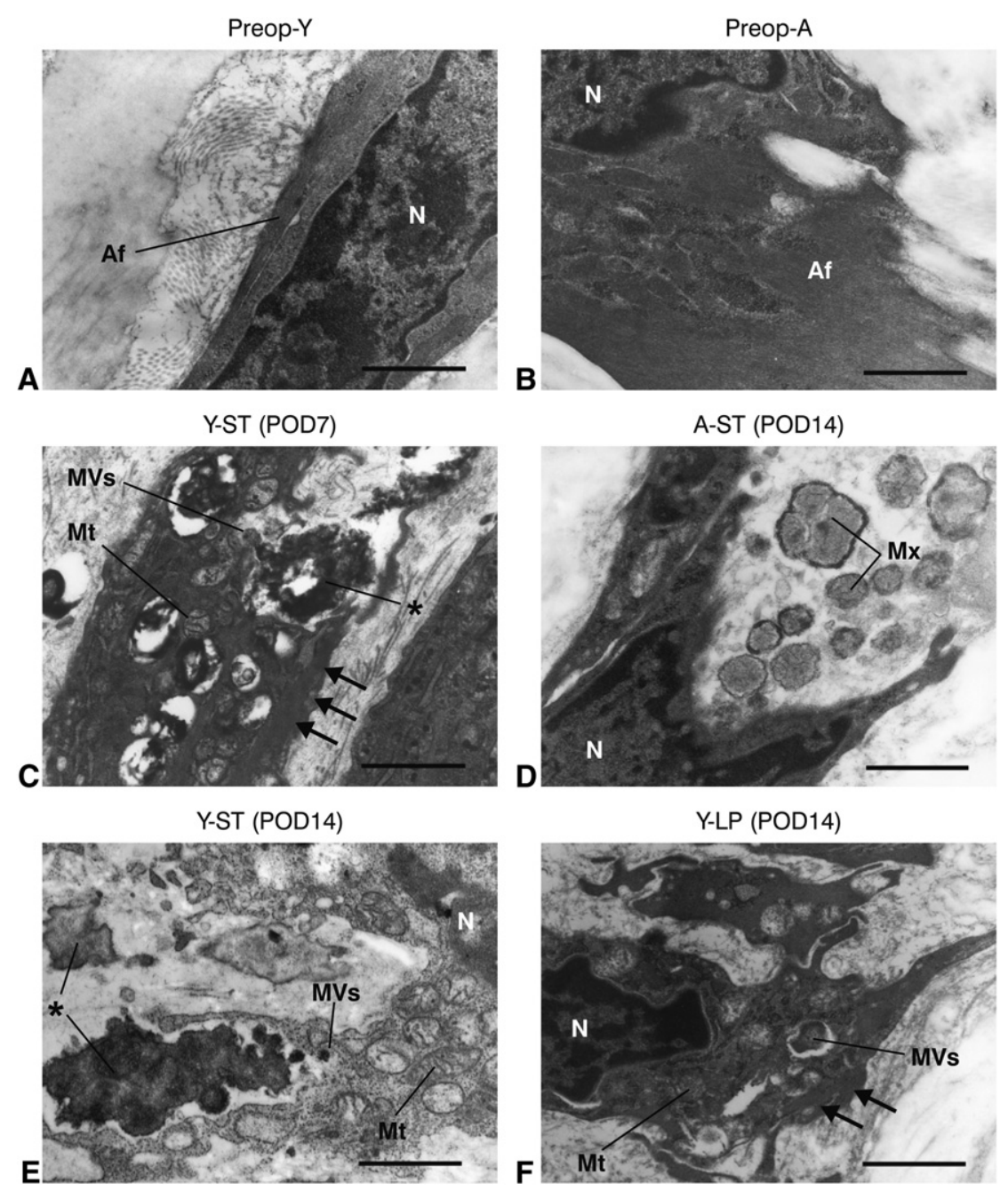

FIGURE 2. Microstructures of the grafts (electron microscopy). The photographs of the grafts were obtained preoperatively (A and B) and at POD 7 from the Y-ST group (C) and at POD 14 from the A-ST, Y-ST, and Y-LP groups (D to F). Arrows indicate actin filaments. Asterisks indicate calcium deposition. $P O D$, Postoperative day; $Y$-ST, young syngeneic-transplant with standard diet; $A$-ST, adult syngeneic-transplant with standard diet; $Y$ - LP, young syngeneictransplant with low inorganic phosphate diet; $N$, nucleus; $A f$, actin filaments; $M t$, mitochondria; $M V s$, matrix vesicles; $M x$, matrix. Magnification $\times 20,000$. $B a r=1 \mu \mathrm{m}$. For abbreviations see Figure 1 .

showed that RAOSMC protein expression had shifted from myogenic ( $\alpha$-SMA) to osteogenic (Runx 2 and osteocalcin) on TNF- $\alpha$ treatment $(50 \mathrm{ng} / \mathrm{mL}$ ) (Figure $4, A)$. Using real-time PCR, the mRNA expression of $\alpha$-SMA in RAOSMCs was significantly down-regulated, whereas those of Runx2, osteocalcin, and Pit-1 were up-regulated by TNF- $\alpha$, both dose-dependently (Figure $4, B$ and $C$ ). Second, we evaluated the coeffects of TNF- $\alpha$ and Pi on RAOSMCs. RAOSMCs were severely calcified on costimulation with TNF- $\alpha(50 \mathrm{ng} / \mathrm{mL})$ and high $\mathrm{Pi}(4.5$ $\mathrm{mmol} / \mathrm{L}$ ), but not with either alone (Figure $4, D$ ). In RAOSMCs, calcium content increased significantly in proportion to the Pi concentration only in the TNF- $\alpha$-treated media $(50 \mathrm{ng} / \mathrm{mL})$ (Figure 4, E). Electron microscopy revealed diminished numbers of actin filaments in RAOSMCs with TNF- $\alpha$, but newly developed rough endoplasmic reticula and matrix vesicles, despite the $\mathrm{Pi}$ concentration in the TNF- $\alpha$-treated media. Calcium deposition in the matrix vesicles appeared only in RAOSMCs treated with high Pi media (Figure 4, F).

\section{DISCUSSION}

In this study, our transplant models demonstrated that aortic allograft calcification, accelerated in young, but not adult, rats, was suppressed by lowering serum Pi to the adult level, suggesting that growth-associated hyperphosphatemia promotes allograft calcification. Not only serum $\mathrm{Pi}$ but also calcium, $1,25(\mathrm{OH})_{2} \mathrm{D}$, and iPTH have been reported to promote vascular calcification. ${ }^{7}$ In the present study, however, the levels of calcium and $1,25(\mathrm{OH})_{2} \mathrm{D}$ were similar in the 2 age groups, and both rose on Pi suppression. Thus, these factors cannot be the primary causes 

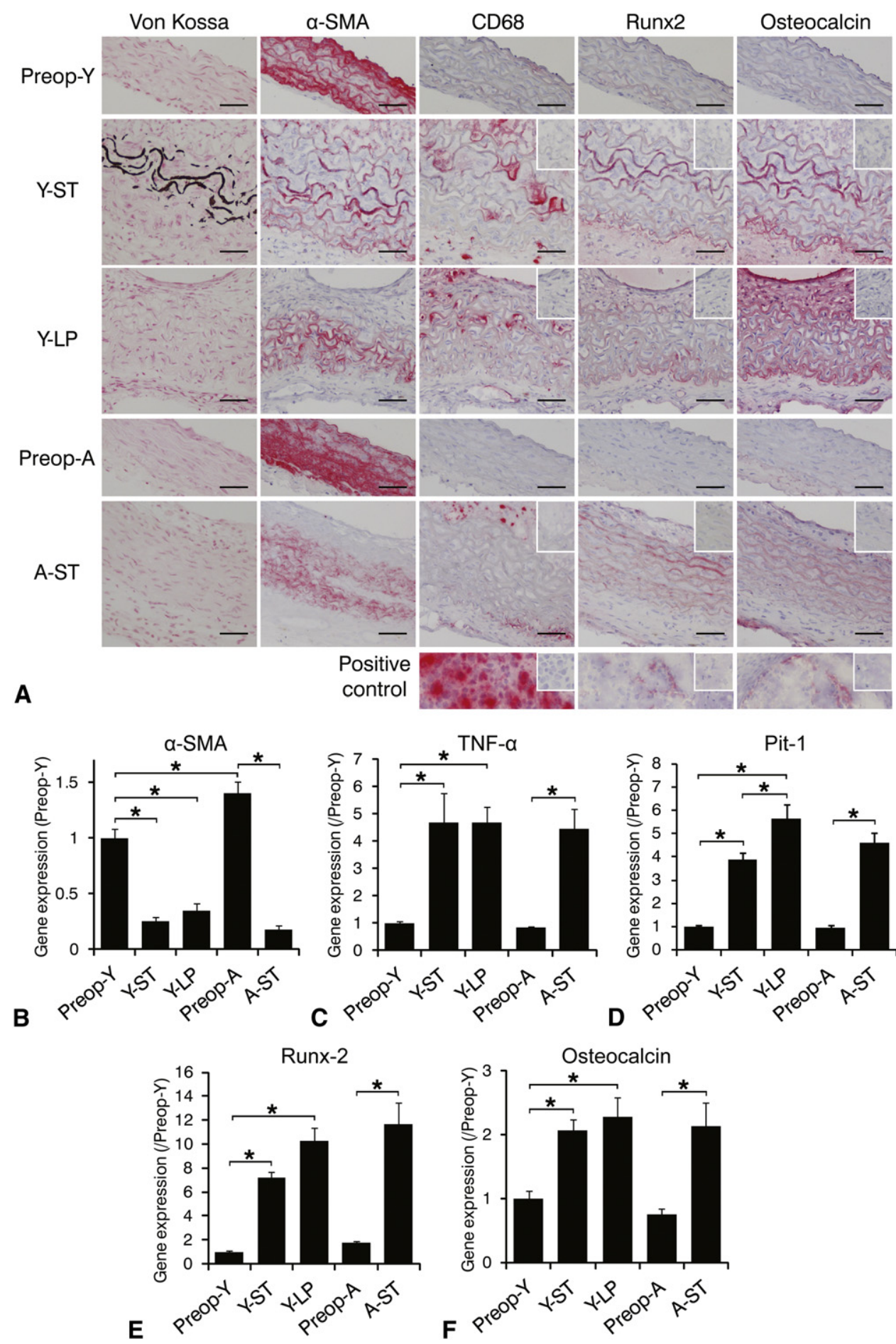

FIGURE 3. Gene expressions in the grafts. A, Von Kossa staining and immunohistochemical stainings of smooth muscle cell-alpha ( $\alpha$-SMA), cluster of differentiation $(C D)$ 68, Runx2, and osteocalcin in the same specimens of syngeneic-transplant group grafts. Protein expression appears red on immunostaining. Positive control: Rat spleen for CD68; rat fetal spine for Runx2 and osteocalcin. Small window: Staining of normal immunoglobulin. Magnification $\times 200$. Bar $=100 \mu \mathrm{m}$. B-F, Real-time polymerase chain reaction $(P C R)$ analyses of $\alpha$-SMA, TNF- $\alpha$, Pit-1, Runx2, and osteocalcin in the grafts. Each gene expression is shown as a ratio of that of the Preop-Y group ( $\mathrm{n}=6$ per group). ${ }^{*} P<.05$ by Tukey-Kramer honestly significant difference test. For abbreviations see Figures 1 and 2. $C D$, Cluster of differentiation; $T N F-\alpha$, tumor necrosis factor-alpha; Pit-1, sodium-phosphate cotransporter; Preop- $Y$, young group before transplantation; $Y$-ST, young syngeneic-transplant with standard diet; $Y$ - $L P$, young syngeneic-transplant with low inorganic phosphate diet; $A-S T$, adult syngeneic-transplant with standard diet; Preop-A, adult group before transplantation. 

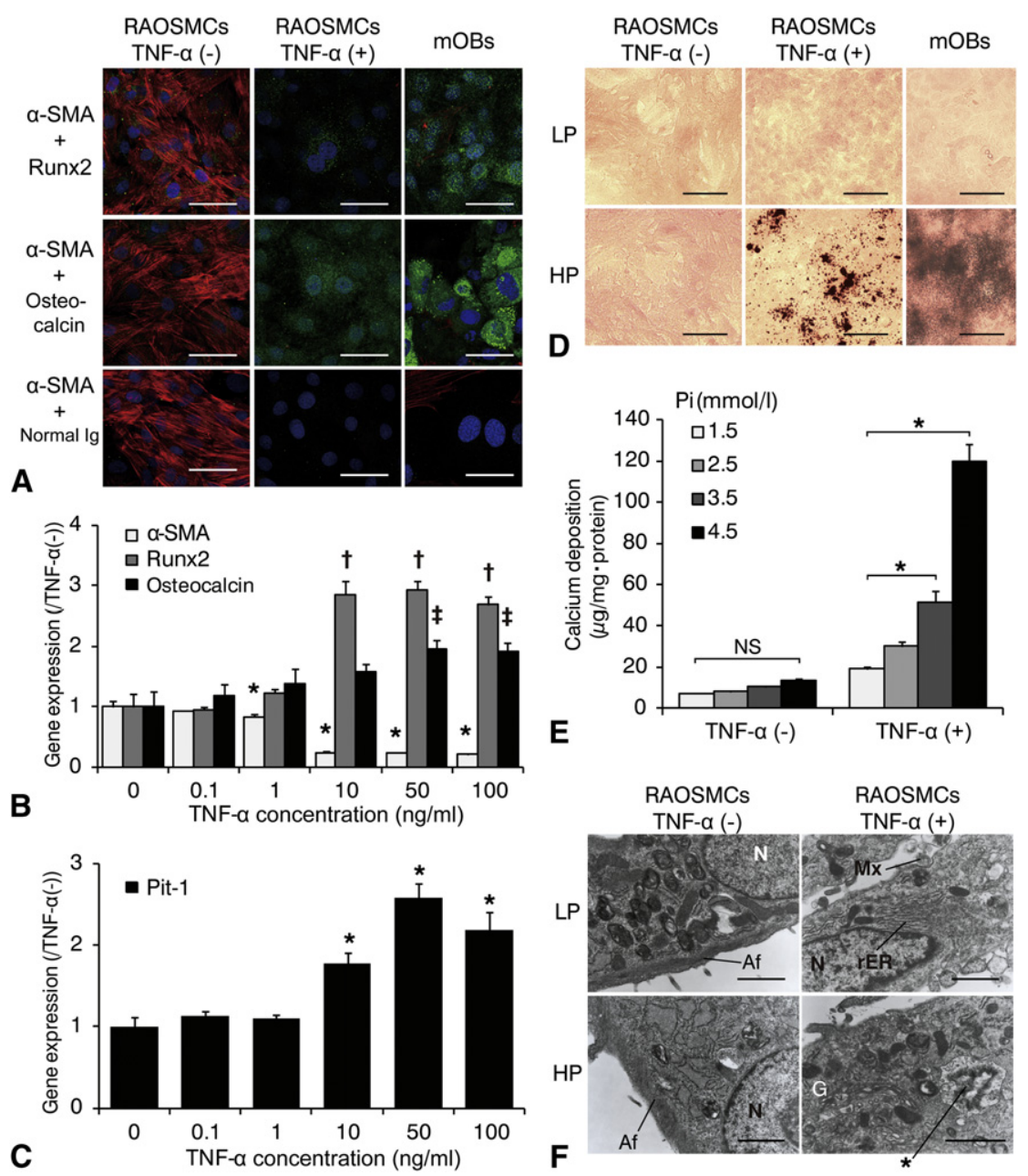

FIGURE 4. Effects of TNF- $\alpha$ and Pi on SMCs. A, Immunocytochemistry of $\alpha$-SMA, Runx2, and osteocalcin proteins in the cultured rat aortic SMCs (RAOSMCs) and mouse osteoblast-like cells ( $\mathrm{mOBs}$; positive control). $\alpha$-SMA antibody was conjugated with Cy3 (red). Runx 2 and osteocalcin antibodies as well as normal immunoglobulin (Ig, negative control) were labeled with Alexa488 (green). Nuclei were counterstained with $4^{\prime}, 6$-diamidino-2phenylindole (DAPI; blue). TNF- $\alpha(+), 50 \mathrm{ng} / \mathrm{mL}$ of TNF- $\alpha$ in the media. Magnification $\times 400$. Bar $=50 \mu \mathrm{m}$. B and C, Real-time PCR analyses of $\alpha$-SMA, Runx2, osteocalcin, and Pit-1. Each gene expression is shown as a ratio of that without TNF- $\alpha(0 \mathrm{ng} / \mathrm{mL})(\mathrm{n}=4$ per group). *, $\dagger, \ddagger P<.05$ compared with $0 \mathrm{ng} / \mathrm{mL}$ of TNF- $\alpha$ using the Dunnett test. D, Calcium deposition is highlighted in black by von Kossa staining. $H P$ and $L P$, high phosphate $(4.5 \mathrm{mmol} / \mathrm{L})$ and low phosphate $(1.5 \mathrm{mmol} / \mathrm{L})$ in the media. Magnification $\times 100$. Bar $=200 \mu \mathrm{m}$. E, Quantified calcium deposition in the RAOSMCs cultured with 1.5 to $4.5 \mathrm{mmol} / \mathrm{L}$ of Pi. ${ }^{*} P<.0001$ by the Dunnett test ( $\mathrm{n}=4$ per group). F, RAOSMCs stimulated by TNF- $\alpha(50 \mathrm{ng} / \mathrm{mL}), \mathrm{HP}$, or both, analyzed by electron microscopy. Asterisk indicates calcium deposition. $G$, Golgi apparatus. Magnifications: the TNF- $\alpha$-HP group, $\times 25,000$; others, $\times 20,000$. Bar $=1 \mu \mathrm{m}$. For abbreviations see Figures 1 to 3. $T N F-\alpha$, Tumor necrosis factor-alpha; $P i$, inorganic phosphate; $S M C$, smooth muscle cell; $\alpha$-SMA, $\alpha$-smooth muscle actin; RAOSMC, rat aortic smooth muscle cell; PCR, polymerase chain reaction. Same as described in the abbreviation box and in the legend of Figure 3.

of graft calcification observed only in the young. The presence of lower iPTH levels in the young than in adults, presumably owing to the effects of growth hormone, ${ }^{14}$ is inconsistent with the hyperparathyroidemia-related ectopic calcification observed in uremia.

Regarding the role of Pi on vascular calcification, in vitro studies reported that high Pi enhanced the Pit-1 expression together with Pi transport and triggered osteogenic transformation of SMCs. ${ }^{8,10}$ However, in the present study, why were the grafts in young animals calcified only after transplantation? And why were osteogenic changes observed in all posttransplant group grafts? Our response to this is to suspect the effects of inflammation in posttransplant grafts. TNF- $\alpha$ expression in posttransplant grafts was enhanced together with the osteogenic markers and Pit-1, irrespective of the animals' ages or diets (Figure 3, C-F). Similar findings are reported in a recent study showing that the aortas of uremic patients, independently of calcification status, enhanced coexpression of TNF- $\alpha$ and bone morphogenetic protein- $2,{ }^{11}$ which is 
a potent regulator of osteoblastic differentiation, ${ }^{24}$ and the expression of the latter was enhanced similarly in the posttransplant grafts in both age groups in our study (data not shown). In vitro, TNF- $\alpha$ acts on vascular calcification through the cyclic adenosine monophosphate/protein kinase A (cAMP/PKA) pathway by enhancing DNA binding of Runx2/Cbfa1 and activating downstream factors, for example, osteocalcin and osteopontin. ${ }^{12}$ More recently, Pi transport via Pit-1 was reported to be a necessary mediator of mineralization downstream from the cAMP/PKA pathway triggered by TNF- $\alpha$, although Pit-1 expression was not enhanced by the cAMP/PKA inducer. ${ }^{25}$ This is inconsistent with our present finding of enhanced Pit-1 concurrent with TNF- $\alpha$ expression in the posttransplant grafts and cultured SMCs, which indicates involvement of a signaling pathway other than cAMP/PKA. Then, our cultured SMCs showing marked calcification only when both TNF- $\alpha$ and high Pi were given were consistent with our transplant model showing significant calcification only in posttransplant grafts in young recipients. These observations suggest that a low Pi diet or Pi binders may prevent allograft calcification in young patients. Considering the limited growth rates observed in the rats fed a low-Pi diet, however, local Pi inhibition or systemic Pi suppression to the threshold level, which can reduce the graft calcification without accompanying growth disturbance, may be necessary.

\section{Study Limitations}

A subcutaneous transplant model using weanling rats has conventionally been used to explore the mechanisms and preventive methods of tissue calcification. ${ }^{17,22}$ The pattern of graft media calcification seen in the allografts after orthotopic implantation resembled that in the present study. ${ }^{26}$ The suggested mechanisms of accelerating graft calcification, however, require validation in circulatory implant models, inasmuch as factors such as blood contact and pulsatile pressure may affect allograft calcification differently. Despite the definite roles of $\mathrm{Pi}$, the influences of other relevant factors on allograft calcification and degeneration, such as immunoreactions, apoptosis, and the function of pyrophosphate, need further investigation. Also, this study has not examined whether the growth retardation was related to the suppression of musculoskeletal development or other hormonal dysfunctions. Further investigation is necessary to clarify the mechanism of this growth retardation and to develop therapeutic strategies with weaker adverse effects.

\section{CONCLUSIONS}

In summary, this rat model suggests that growthassociated hyperphosphatemia in young recipients, in conjunction with osteogenic transformation of graft medial SMCs, may be critical in promoting vascular allograft calcification and is therefore potentially a therapeutic target for inhibiting allograft calcification and improving graft durability in young recipients.

We are grateful to Mr Satoru Fukuda for technical advice regarding electron microscopy and to $\mathrm{Mr} \mathrm{C}$. W. P. Reynolds for his careful linguistic assistance with this manuscript.

\section{References}

1. Fontan F, Choussat A, Deville C, Doutremepuich C, Coupilland J, Vosa C. Aortic valve homografts in the surgical treatment of complex cardiac malformations. $J$ Thorac Cardiovasc Surg. 1984;87:649-57.

2. Clarke DR, Campbell DN, Hayward AR, Bishop DA. Degeneration of aortic valve allografts in young recipients. J Thorac Cardiovasc Surg. 1993;105: 934-41.

3. Tweddell JS, Pelech AN, Frommelt PC, Mussatto KA, Wyman JD, Fedderly RT, et al. Factors affecting longevity of homograft valves used in right ventricula outflow tract reconstruction for congenital heart disease. Circulation. 2000; 102(Suppl III):III130-5.

4. Yankar AC, Alexi-Meskhishvili V, Weng Y, Schorn K, Lange PE, Hetzer R. Accelerated degeneration of allografts in the first two years of life. Ann Thorac Surg. 1995;60(Suppl):S71-6.

5. Shaddy RE, Hawkins JA. Immunology and failure of valved allografts in children. Ann Thorac Surg. 2002;74:1271-5.

6. Vattikuti R, Towler DA. Osteogenic regulation of vascular calcification: an early perspective. Am J Physiol Endocrinol Metab. 2004;286:E686-96.

7. Querfeld U. The clinical significance of vascular calcification in young patients with end-stage renal disease. Pediatr Nephrol. 2004;19:478-84.

8. Jono S, McKee MD, Murry CE, Shioi A, Nishizawa Y, Mori K, et al. Phosphate regulation of vascular smooth muscle cell calcification. Circ Res. 2000;87: E10-7.

9. Steitz SA, Speer MY, Curinga G, Yang HY, Haynes P, Aebersold R, et al. Smooth muscle cell phenotypic transition associated with calcification: upregulation of Cbfa1 and downregulation of smooth muscle lineage markers. Circ Res. 2001; 89:1147-54

10. Li X, Yang HY, Giachelli CM. Role of the sodium-dependent phosphate cotransporter, Pit-1, in vascular smooth muscle cell calcification. Circ Res. 2006;98: 905-12.

11. Koleganova N, Piecha G, Ritz E, Schirmacher P, Müller A, Meyer HP, et al. Arterial calcification in patients with chronic kidney disease. Nephrol Dial Transplant. 2009;24:2488-96.

12. Tintut Y, Patel J, Parhami F, Demer LL. Tumor necrosis factor-alpha promotes in vitro calcification of vascular cells via the cAMP pathway. Circulation. 2000;102:2636-42.

13. Shioi A, Katagi M, Okuno Y, Mori K, Jono S, Koyama H, et al. Induction of bonetype alkaline phosphatase in human vascular smooth muscle cells: roles of tumor necrosis factor-alpha and oncostatin $\mathrm{M}$ derived from macrophages. Circ Res. 2002;91:9-16

14. Woda CB, Halaihel N, Wilson PV, Haramati A, Levi M, Mulroney SE. Regulation of renal NaPi-2 expression and tubular phosphate reabsorption by growth hormone in the juvenile rat. Am J Physiol Renal Physiol. 2004;287: F117-23.

15. Price PA, Faus SA, Williamson MK. Warfarin-induced artery calcification is accelerated by growth and vitamin D. Arterioscler Thromb Vasc Biol. 2000;20: 317-27.

16. Subcommittee on Laboratory Animal Nutrition, Committee on Animal Nutrition, Board on Agriculture, National Research Council. Nutrient Requirements of the Laboratory Rat. In: Subcommittee on Laboratory Animal Nutrition, National Research Council, editor. Nutrient requirements of laboratory animals. 4th revised ed. Washington (DC): The National Academies Press; 1995. p. 27-8.

17. Webb CL, Nguyen NM, Schoen FJ, Levy RJ. Calcification of allograft aortic wall in a rat subdermal model. Pathophysiology and inhibition by $\mathrm{Al}^{3+}$ and aminodiphosphonate preincubations. Am J Pathol. 1992;141:487-96.

18. Moorehead WR, Biggs HG. 2-Amino-2-methyl-1-propanol as the alkalizing agent in an improved continuous-flow cresolphthalein complexone procedure for calcium in serum. Clin Chem. 1974;20:1458-60.

19. Drewes PA. Direct colorimetric determination of phosphorus in serum and urine Clin Chim Acta. 1972;39:81-8.

20. Saito A, Motomura N, Kakimi K, Narui K, Noguchi N, Sasatsu M, et al. Vascula allografts are resistant to methicillin-resistant Staphylococcus aureus through 
indoleamine 2,3-dioxygenase in a murine model. J Thorac Cardiovasc Surg. 2008;136:159-67.

21. Sata M, Tanaka K, Ishizaka N, Hirata Y, Nagai R. Absence of p53 leads to accelerated neointimal hyperplasia after vascular injury. Arterioscler Thromb Vasc Biol. 2003;23:1548-52.

22. Brockbank KG, Song YC. Mechanisms of bioprosthetic heart valve calcification. Transplantation. 2003;75:1133-5.

23. Henke W, Herdel K, Jung K, Schnorr D, Loening SA. Betaine improves the PCR amplification of GC-rich DNA sequences. Nucleic Acids Res. 1997;25:3957-8.
24. Hruska KA, Mathew S, Saab G. Bone morphogenetic proteins in vascular calcification. Circ Res. 2005;97:105-14.

25. Huang MS, Sage AP, Lu J, Demer LL, Tintut Y. Phosphate and pyrophosphate mediate PKA-induced vascular cell calcification. Biochem Biophys Res Commun. 2008;374:553-8.

26. Flameng W, Jashari R, De Visscher G, Mesure L, Meuris B. Calcification of allograft and stentless xenograft valves for right ventricular outflow tract reconstruction: an experimental study in adolescent sheep. J Thorac Cardiovasc Surg. 2011;141:1513-21. 